\title{
Atuação da OTAN no Pós-Guerra Fria: Implicações para a Segurança Internacional e para a ONU*
}

\author{
Juliana Bertazzo**
}

\section{Introdução}

A Organização do Tratado do Atlântico Norte (OTAN) foi criada pelo Tratado de Washington, um instrumento que estabeleceu simultaneamente seu caráter de aliança militar e sua expressão institucional, na forma de uma organização internacional. Consta do texto original do tratado, redigido em 1949, além das disposições sobre a garantia da paz inter alia e sobre segurança coletiva, a forma de sua dimensão institucional: a decisão de estabelecer imediatamente um

\footnotetext{
* Artigo recebido em agosto de 2008 e aprovado para publicação em maio de 2010. A autora agradece à Fundação de Amparo à Pesquisa do Estado de São Paulo (FAPESP) pelo apoio financeiro.

** Doutora em Ciência Política pela Universidade Estadual de Campinas (Unicamp) e pesquisadora da Berghof Foundation for Conflict Studies. E-mail: jbertazzo@gmail.com.
} 
conselho para que os membros pudessem se reunir a qualquer momento.

Este conselho poderia, por sua vez, estabelecer corpos subsidiários, "tantos quantos forem necessários", e em particular um comitê de defesa (OTAN, 1949, art. 9). Tal agência estaria encarregada de supervisionar o desenvolvimento de capacidades individuais e coletivas para resistir a um ataque armado e organizar os atores para que esta resistência fosse efetiva.

O quartel-general da OTAN fundar-se-ia nas proximidades de Paris apenas dois anos após a assinatura do Tratado de Washington. Logo em 1952, dois novos membros seriam convidados a integrar a Aliança. A ratificação do acordo pela Grécia e pela Turquia fez com que a organização, de uma só vez, deixasse de ser um elo apenas entre a Europa e os Estados Unidos, e também perdesse fundamentalmente a ligação com o Atlântico Norte. A expressão "ao norte do Trópico de Câncer" passou a representar melhor a abrangência da Aliança.

Desde o fim da Guerra Fria, entretanto, a OTAN passou por uma série de mudanças e persistiu, mesmo diante do fim do conflito Leste-Oeste. Em um período de apenas dois anos, a OTAN perdeu dois dos principais motivos de sua fundação: a ameaça soviética e a Alemanha Oriental socialista. ${ }^{1}$

Foi estabelecido um sistema de cooperação com a Federação Russa e outros membros do Pacto de Varsóvia, a começar pela ex-Alemanha Oriental, que foram convidados a integrar a Aliança, com requerimentos específicos para a garantia do acesso (SIMON, 1996).

Internamente, a organização também passou por constantes mudanças, a começar por sua doutrina, o seu conceito estratégico (OTAN, 1991). A partir de então, os organogramas da organização têm mudado constantemente, assim como as suas concepções estratégicas, 
Atuação da OTAN no Pós-Guerra Fria: Implicações para a Segurança Internacional...

para se adaptar às constantes alterações de cenários e emergência de novas ameaças (SMITH, 1997).

Logo no começo da década de 1990, em função dos conflitos nos Bálcãs, a OTAN declarou que a instabilidade na Europa Central afetava diretamente a segurança de seus membros. Foi então iniciada a primeira operação militar da OTAN fora do território dos paísesmembros. O objetivo deste primeiro engajamento militar da OTAN na sua história era monitorar um embargo aéreo sobre o território da ex-Iugoslávia, atendendo a um pedido da Organização das Nações Unidas (ONU). É importante lembrar que esta ação não foi motivada por uma ameaça ou ataque real à OTAN por parte do Estado onde foi desenvolvida a ação militar. Ao contrário, a OTAN atuou neste conflito apenas como uma força de restabelecimento da paz, sem montar aliança alguma com uma parte no conflito. Esta foi apenas a primeira de uma série de atuações com e sem mandatos da ONU e, desde então, a OTAN expandiu sua área de interesse para além da Europa e passou a atuar também na África, no Oriente Médio e na Ásia.

Por que a OTAN, que atravessa a Guerra Fria sem engajamento militar algum, tem um grande ativismo no período pós-Guerra Fria, quando se espera que ela deixe de ser relevante ou necessária? Por que ela passa a atuar além da sua região, em outras áreas do globo em operações de manutenção de paz? Para melhor entender a nova fase da OTAN e suas consequências para a segurança internacional, é preciso estudar o impacto de sua transformação em relação às missões que esta cumpria durante a Guerra Fria (CORNISH, 2004; SMITH, 2000).

Este trabalho analisa a possível redução no ativismo humanitário da ONU em termos absolutos e em relação ao aumento do ativismo da OTAN. A hipótese principal é de que o ativismo da OTAN busca suprir uma redução da atuação da ONU. Contudo, uma hipótese secundária é de que a própria dinâmica interna da OTAN tem consequênci- 
as importantes para este fenômeno. As teorias das alianças e as teorias das instituições e organizações, apresentadas a seguir, oferecem-nos elementos para analisar as mudanças pelas quais ainda passa a OTAN, e que refletem uma mudança mais ampla em conceitos de segurança internacional.

Além disso, uma análise jurídica do papel da OTAN na manutenção da paz internacional, também realizada neste trabalho, lança luz sobre as consequências do fenômeno de sua atuação global e sua crescente autonomia em relação ao Conselho de Segurança da ONU. Esta situação tem dois problemas fundamentais: primeiro, a autonomia da OTAN enquanto organização vai de encontro às previsões do direito internacional para a atuação de agências regionais de segurança; segundo, tampouco se justifica o envolvimento da OTAN enquanto aliança militar em operações de manutenção de paz, pois nesse caso ela não é parte em um conflito armado.

\section{A OTAN enquanto Aliança}

A literatura sobre alianças, um fenômeno central das relações internacionais, concentra-se na análise da formação e da dinâmica desse tipo de arranjo, mas falha ao explicar sua persistência. É esperado que uma aliança criada para dissuadir um potencial agressor se dissolva assim que a ameaça que a motivou esteja extinta. Por que, então, uma aliança militar em particular, a OTAN, não se esvaziou quando a principal ameaça aos seus membros deixou de existir? Ao contrário, esta organização se expandiu, acolhendo inclusive membros do arranjo anteriormente identificado como potencial agressor (Pacto de Varsóvia) e removendo os limites à sua ação impostos pela condição estrita de aliança militar. Poderia uma aliança se organizar para agir imparcialmente em um conflito alheio aos seus membros, como é o caso das operações de paz? A literatura sobre alianças oferece algumas tentativas de resposta a estas indagações. 
Atuação da OTAN no Pós-Guerra Fria: Implicações para a Segurança Internacional...

Entre as teorias mais influentes sobre as alianças, podemos destacar a teoria dos jogos e a teoria do equilíbrio de poder (também conhecida como balança de poder), que está presente em grande parte dos estudos da área de Relações Internacionais. A ideia de um equilíbrio de forças entre unidades políticas já foi observada por David Hume no mundo antigo (BULL, 1977, p. 101) e, na visão de Raymond Aron (1986, p. 189), esta é uma regra de bom-senso e sobrevivência: nenhum dos Estados deve ter força tal que incapacite uma coalizão de Estados vizinhos a defender seus direitos contra um ataque que parta dele.

A teoria realista das Relações Internacionais, em sua formulação tradicional, estabelece que a distribuição das capacidades de cada Estado no sistema internacional determina as posições de cada um na luta pelo poder. Uma das definições oferecidas por Hans J. Morgenthau (1993, p. 26) para o equilíbrio de poder é: "mecanismo autorregulatório das forças sociais que se manifesta na luta por poder no cenário internacional".

Em outras palavras, o equilíbrio de poder é uma configuração resultante das políticas dos Estados na luta pelo poder. Este tipo de interação pode levar à guerra, porque sua função é manter o sistema de Estados, e não necessariamente garantir a paz. Hedley Bull (1977) estuda os tipos e as funções dos equilíbrios de poder e observa que a preservação deste equilíbrio tem relações com o direito internacional. Embora as potências possam sempre desrespeitar a soberania de seus vizinhos localmente, absorvendo seus territórios, um equilíbrio de poder geral impede que isso seja feito em escala mundial.

Para grande parte dos realistas, as alianças maximizam essencialmente a segurança dos Estados, e não necessariamente seu poder, justamente porque não são concebidas como arranjos permanentes. Alianças podem contribuir para o estabelecimento de um equilíbrio de poder, a fim de neutralizar distúrbios causados pela emergência de 
um adversário poderoso. Enfim, as alianças não são estáveis por duas razões: primeiro, porque limitam a liberdade dos Estados para agir em função de seu interesse nacional; e, segundo, porque podem fortalecer os aliados do presente, sempre possíveis adversários do futuro.

No equilíbrio de poder geral, um Estado mais poderoso será contraposto a uma aliança de poderes menores, que se unirão para equilibrar as forças existentes no cenário internacional e impedir a formação de um império global. Esse mecanismo está fundado em grande medida na estratégia da dissuasão, que incentiva o aumento do poder de um Estado de tal forma que desencoraje o ataque de outro, o qual deverá desistir ao perceber a certeza do fracasso. ${ }^{2}$ Uma das premissas desta teoria é a racionalidade dos atores, neste caso, os Estados, que agem a partir de um cálculo estratégico.

Já a teoria dos jogos, também baseada na racionalidade dos atores, introduz, além da ideia de busca do equilíbrio, a ideia oposta, de que os atores podem decidir se aliar ao Estado mais poderoso. Em vez de se contrapor a um possível ator hegemônico, de forma a equilibrar o sistema, Estados mais fracos unir-se-iam a ele. Esta seria a atitude dos chamados "caronas", 3 que decidem se aliar ao Estado mais forte para não pagarem os custos envolvidos na estratégia da dissuasão.

Muitos desses estudos têm como base a racionalidade econômica atribuída aos atores na teoria dos bens coletivos, com destaque para a contribuição de Mancur Olson. A impossibilidade de restringir a alguns membros de uma aliança os benefícios gerados pela mesma faz com que ela seja considerada uma espécie de bem coletivo (OLSON; ZECKHAUSER, 1966). No ambiente da Guerra Fria, os Estados mais fracos utilizavam a disputa ideológica para valorizar seu alinhamento e, assim, conseguir vantagens. A tentação de embarcar em uma aliança junto com o Estado mais forte expõe um Estado mais 
Atuação da OTAN no Pós-Guerra Fria: Implicações para a Segurança Internacional...

fraco, contudo, ao risco de abandono, quando o mais forte não tem interesse em seu apoio.

Muitas críticas foram feitas a estas abordagens tradicionais do fenômeno das alianças. Entre as mais relevantes para o nosso objeto de estudo, encontramos a de Avery Goldstein (1995), que critica o argumento de Mancur Olson, sugerindo que os benefícios para a segurança, surgidos a partir de uma aliança, necessariamente falham no teste de impossibilidade de exclusão. Isso porque os Estados estão imersos em um ambiente anárquico que permite que seu comportamento se desvie significativamente daquele esperado pela teoria dos bens coletivos.

Este mesmo autor desqualifica o argumento de que a dissuasão, inclusive a nuclear, existente na Guerra Fria reforce os incentivos para que os atores se tornem “caronas". Muito pelo contrário, ele acredita que a bipolaridade e os armamentos nucleares exacerbaram as dúvidas dos aliados sobre a provisão de segurança por parte das potências líderes. Goldstein (1995) estuda os casos da Grã-Bretanha, França e China durante a Guerra Fria. Em função da desconfiança em relação ao compromisso de seus líderes, estes três atores, conquanto mantivessem seu alinhamento a uma das superpotências, deixaram de ser "caronas" para tentar garantir sua própria segurança, investindo em defesa e adquirindo suas próprias armas nucleares.

Percebemos até aqui que as alianças não são formadas de forma neutra, imparcial para atuação desinteressada em um conflito alheio. Qual seria, então, o comportamento típico dos atores na formação de alianças? Seriam eles mais inclinados a equilibrar ou a reforçar o poder de um Estado mais forte? Stephen M. Walt (1988) analisou as políticas externas do Irã, da Turquia, da Índia e do Paquistão na Guerra Fria. Sua conclusão a partir dos casos apresentados é que o equilíbrio de poder é a opção mais frequente. A América Latina é lembrada, porém, como uma notável exceção a esta regra. Durante a Guerra Fria, 
os Estados latino-americanos pegaram carona sob a influência do poder dos Estados Unidos e esperaram que este país agisse em favor da segurança de cada um dos aliados do continente. Não houve sequer um mimetismo do comportamento da França, da Grã-Bretanha ou da China, descrito por Goldstein (1995). Tal atitude seria irracional de acordo com a teoria do equilíbrio de poder, pois, antes de qualquer outra consideração, o próprio aumento do poder dos Estados Unidos deveria representar uma ameaça aos seus vizinhos, que deveriam tentar prover a própria segurança ou então buscar uma aliança com a União Soviética.

A teoria do equilíbrio de ameaças, desenvolvida por Stephen Walt (1988), é capaz de explicar até mesmo tal comportamento anômalo dos latino-americanos. Segundo esta teoria mais geral, o poder é apenas uma das fontes de ameaças aos Estados. O grau em que um Estado ameaça o outro é o produto de seu poder agregado, proximidade geográfica, capacidade ofensiva e agressividade de suas intenções. Desequilíbrios de ameaças, e não apenas de poder, promoveriam a formação de alianças contra o Estado mais ameaçador.

No caso da América Latina, as intenções dos Estados Unidos não eram vistas como agressivas. Mesmo tendo realizado várias intervenções, direta ou indiretamente, nos países da região, a contenção do comunismo era um objetivo declarado dos Estados Unidos, e que ia ao encontro dos interesses das elites dominantes locais em toda a região. Isso porque tal política preservaria sua posição dominante, que seria provavelmente abalada pela instalação do comunismo. Walt (1988) afirma, contudo, que os Estados Unidos erraram ao considerar que as questões ideológicas fossem determinantes para o alinhamento. De fato, coalizões sempre foram possíveis entre Estados de estruturas internas diferentes, e muitas vezes mantidas mesmo quando as estruturas internas se alteravam. 
Atuação da OTAN no Pós-Guerra Fria: Implicações para a Segurança Internacional...

A teoria do equilíbrio de ameaças, elaborada por Walt, pode ser vista como um refinamento da teoria do equilíbrio de poder. Ela pode explicar parte das políticas da OTAN no pós-Guerra Fria; por exemplo, a sua expansão em direção ao leste da Europa. Ainda assim, ela não explica a persistência das alianças, quando excluídas as ameaças que motivaram sua formação, como é o caso da OTAN.

O Tratado de Washington previa uma reavaliação de seus termos após dez anos em vigor, seja em função de uma mudança de cenário para a segurança regional ou do desenvolvimento de outros mecanismos sob a Carta da ONU. Após vinte anos de vigência, estava também prevista a possibilidade de denúncia por parte de qualquer um dos membros, desde que avisassem aos outros com um ano de antecedência.

Embora seu próprio instrumento de fundação contivesse as cláusulas de seu possível encerramento, o Tratado de Washington só registrou adesões nos primeiros vinte anos de existência, atravessou mais de quatro décadas de Guerra Fria sem alterações e já completou 60 anos, sem denúncia alguma. Muito pelo contrário, o fim do conflito bipolar registrou adesão recorde, mais que dobrando o número de membros fundadores, e existe uma lista de espera de candidatos a adesão. Nem mesmo o fim da ameaça que motivou sua adesão inicial foi uma mudança suficiente, na avaliação dos membros, para determinar o seu próprio fim.

Diferentemente de outras organizações criadas após a Segunda Guerra Mundial, o texto do tratado deixa claro que a OTAN não foi concebida como um arranjo permanente. Não ignorando este caso, e reconhecendo que a OTAN possui um caráter dual, de aliança e organização, a literatura também procura explicar a persistência desta aliança utilizando a teoria institucional e a dos regimes. 


\section{A OTAN enquanto} Organização

Vimos que a OTAN é uma aliança militar que se funda sobre um tratado de segurança coletiva, o qual, por sua vez, indica a criação de uma organização internacional com o objetivo de manter a paz e a segurança entre seus membros e a democracia dentro deles (WALLANDER, 2000). Além da questão militar, o Tratado de Washington também menciona condições políticas e até econômicas para a estabilidade e a paz entre os aliados e propõe a criação de um fórum e outras estruturas para que eles coordenem políticas. Como lembrado há pouco, esse texto já continha as cláusulas de seu possível encerramento: previa uma reavaliação de seus termos após dez anos em vigor e, após vinte anos de vigência, estava também prevista a possibilidade de denúncia por parte de qualquer um dos membros.

Este tratado, entretanto, nunca recebeu uma denúncia ou emenda, e mesmo com uma mudança de cenário, o fim da Guerra Fria, apenas registrou a adesão de novos membros. Somados, o total de novos membros é maior que o número original de doze Estados fundadores. Além disso, a expansão da OTAN teve um sentido claro de abrigar sob sua proteção o território do arranjo anteriormente adversário, o Pacto de Varsóvia, com a notável exceção da Federação Russa.

Algumas alianças podem continuar a existir apenas enquanto tratados, públicos ou secretos, mas perdem seus efeitos em geral com a falta de compromisso dos membros. Um exemplo é o Tratado Interamericano de Assistência Recíproca (TIAR), ou Pacto do Rio, que não é o documento que serviu como carta para a criação da Organização dos Estados Americanos (OEA). ${ }^{4}$

Esperava-se que a Aliança Atlântica não sobreviveria ao fim do conflito, pois os próprios membros veriam-na como irrelevante. As organizações, contudo, tendem a permanecer. No estudo da OTAN, portanto, a sua dimensão institucional e organizacional, estabelecida 
Atuação da OTAN no Pós-Guerra Fria: Implicações para a Segurança Internacional...

desde a fundação da aliança militar, pode ser a chave para a compreensão de sua permanência e de seu novo papel ao fim do conflito bipolar.

Embora o ambiente pós-Guerra Fria tivesse gerado um desequilíbrio de poder favorável aos aliados da OTAN, esta não se dissolveu. Todas as demais previsões dos neorrealistas, apoiados na teoria das alianças, se concretizaram: a OTAN de fato cortou custos, de certa forma renacionalizou a defesa ${ }^{5}$ e seus membros buscaram outras formas de cooperação internacional, notadamente, dentro da Política Europeia de Segurança e Defesa (PESD). A teoria organizacional prevê que os interesses da instituição, mais que os dos membros, devem manter seu funcionamento quando ela se encontra neste tipo de situação. Robert B. McCalla (1996) mostra que os membros também têm o desejo de manter uma organização existente, ao invés de criar uma nova (o que implicaria em custos extras) para cumprir novas tarefas.

Em seu estudo sobre a permanência da OTAN, Robert McCalla (1996) propõe três níveis de análise: 1) a dinâmica do comportamento da OTAN enquanto organização; 2) a relação entre seus membros dentro do regime de segurança que envolve a OTAN; e 3) as políticas domésticas de seus membros. Quanto ao comportamento da OTAN, o autor destaca, entre as várias mudanças que a organização sofreu, uma mudança de objetivo: ela deixa de se preparar para reagir a um ataque de um adversário claramente definido para se voltar à contenção de conflitos localizados, ao apoio à defesa civil na ocasião de emergências e à luta contra o terrorismo.

A OTAN passou por todas as posições possíveis para organizações em face de mudanças fundamentais: negação da mudança, afirmação própria e adaptação. Um exemplo da negação da mudança é que a Rússia permaneceu como uma ameaça aos aliados no conceito estratégico da organização, mesmo com o fim da União Soviética. 
Podemos dizer, contudo, que a posição mais importante para sua persistência tenha sido a adaptação. Afirmar que a ameaça do arsenal soviético ainda era preocupante não sustentaria uma aliança daquela magnitude: a OTAN teve que mudar seu comportamento e logo transformou o ex-adversário em aliado, quando forças russas integraram uma missão da OTAN na Bósnia-Herzegovina. É importante lembrar que a Rússia já integrava, desde a détente, um arranjo de cooperação com os países-membros da OTAN, a Conferência para Segurança e Cooperação na Europa (CSCE), que se tornou uma organização (identificada como OSCE) após o fim da Guerra Fria.

O Tratado de Washington não menciona a União Soviética como ameaça, indicando apenas um possível "ataque armado" ou "fatores que afetem a paz e a segurança dos membros", ou seja, não identifica um inimigo em particular (OTAN, 1949). Pode-se, então, afirmar que, de certa forma, a OTAN continua mantendo sua missão principal de preservar a segurança de seus membros, ainda que o contexto mundial e, principalmente, as ameaças à segurança de seus membros tenham mudado radicalmente. Aqui está uma abertura para a inclusão de novas missões. Prova disso é que, no discurso dos membros, figura como um dos objetivos precípuos da OTAN a estabilidade internacional em um sentido mais amplo, além da mera estabilidade inter alia.

Já a teoria institucional vê a OTAN como parte de uma ampla relação entre seus membros, que abrange vários assuntos e se dá em vários níveis. Tal relação está baseada em normas e regras implícitas e explícitas, ou seja, constitui um regime. A literatura de regimes é clara quanto aos benefícios que eles podem trazer, sendo o principal deles a redução da insegurança dos atores, por meio do aumento do custo de uma ação desviante das regras. Em uma Europa historicamente dividida entre múltiplas rivalidades, esse benefício é sensível (DUFFIELD, 1992). Quanto aos constrangimentos, podemos dizer que os Estados Unidos conseguiram manter sua supremacia como lí- 
Atuação da OTAN no Pós-Guerra Fria: Implicações para a Segurança Internacional...

der da aliança mesmo com o desenvolvimento das capacidades dos outros membros, as quais, contudo, ainda não se igualaram à sua (YOST, 1998).

Em resumo, a abordagem institucionalista prevê que os membros da OTAN procurarão mantê-la: 1) utilizando suas normas e procedimentos já internalizados para lidar com novas ameaças, em vez de criar novas regras; 2 ) modificando sua estrutura organizacional para adaptá-la aos novos problemas; 3) utilizando esse mesmo regime para se ligar a outros atores a fim de realizar os objetivos dos membros do regime.

Os membros da OTAN tomaram todas estas medidas por meio do engajamento em operações de paz, das diversas reestruturações internas e do estabelecimento de programas, tais como a Parceria para a Paz (em inglês, Partnership for Peace (PfP)) com países da Eurásia, o Diálogo Mediterrâneo (MD) com países do Norte da África, e também da cooperação com a União Europeia e com a ONU. Na Cúpula de Istambul, em 2004, foi lançado inclusive um programa de cooperação com o Oriente Médio, a Iniciativa de Cooperação de Istambul (OTAN, 2004).

A OTAN foi além da área político-militar prevista no seu formato institucional original. Em maior ou menor grau de coordenação, constituiu-se uma comunidade política, sendo um fórum para discussão dos assuntos de interesse comum dos membros. Mais recentemente, também diversificou sua ação por meio da criação de programas nas mais diversas áreas. Meteorologia, educação, pesquisa científica e ambiental estão entre os temas de programas especiais desta organização.

Quanto aos fatores internos analisados pela teoria institucional, podemos destacar o papel de fórum consultivo desempenhado pela OTAN desde a sua fundação, e previsto no Tratado de Washington. $\mathrm{O}$ alto nível de coordenação de políticas externas e a efetiva resolução 
de disputas possibilitada pela estrutura desta organização fazem com que ela ultrapasse a definição de uma aliança militar comum, cumprindo as funções de uma organização política e tornando-se um instrumento valioso de política externa para seus membros, do qual eles não estão dispostos a abrir mão (DUFFIELD, 1994).

\section{A atuação da OTAN no pós-Guerra Fria}

Apesar de poder ser considerada uma organização regional de segurança, desde o fim da Guerra Fria a OTAN tem incrementado sua área de atuação, para além do que dispõe o Capítulo VIII da Carta das Nações Unidas. O artigo 52 deste capítulo permite a criação de tais agências para a ação regional, desde que sob os princípios e propósitos da ONU (ONU, 1949, art. 52).

No texto deste documento, fica estabelecido que as organizações regionais de segurança devem tentar resolver disputas locais entre seus membros antes de levá-las ao Conselho de Segurança da ONU, e que este poderá utilizá-las para fazer cumprir suas decisões. Contudo, o artigo 53 prevê que nenhuma medida coercitiva poderá ser tomada por estas agências sem autorização prévia do Conselho de Segurança, salvo medidas contra Estados considerados inimigos segundo o artigo 107 da mesma Carta, ou seja, os Estados inimigos de qualquer signatário da Carta durante a Segunda Guerra Mundial (ONU, 1949, art. 53).

O envolvimento da OTAN em operações de paz e de ajuda humanitária é um dos pontos mais controversos da nova fase da Aliança. Como a organização tem caráter de uma aliança puramente militar, suas operações não possuem componente civil. Além disso, com questionável legitimidade, desde a primeira ocasião do emprego das forças armadas da OTAN em missões de paz, em apoio a uma operação da ONU na Bósnia-Herzegovina, a OTAN adquiriu uma relativa inde- 
Atuação da OTAN no Pós-Guerra Fria: Implicações para a Segurança Internacional...

pendência em relação à ONU. Apesar de vários questionamentos sobre a sua atuação expedicionária, em função de seu caráter regional de adesão restrita, a maior parte das operações da OTAN não partiu de iniciativa própria, mas sim de pedidos externos. A OTAN já atendeu, inclusive, um pedido de intervenção vindo diretamente de um chefe de Estado não-membro, o Paquistão, ${ }^{6}$ e já atuou repetidamente na África atendendo pedidos da União Africana (UA).

Ao final de 2008, a OTAN mantinha sete operações em andamento (OTAN, 2008a), o que corresponde a aproximadamente metade do número de operações mantidas no mesmo momento pela ONU. ${ }^{7}$ Enquanto as operações da ONU estão dispersas entre os cinco continentes, a OTAN não se restringe ao território dos países-membros nem à Europa e opera atualmente também na África, no Oriente Médio e no sul da Ásia, conforme mostra a Tabela 1.

\section{Tabela 1}

Lista Completa das Operações da OTAN em Andamento (Dezembro/2008)

\begin{tabular}{ll}
\hline Operação & Localidade \\
\hline ISAF & Afeganistão \\
SFOR* & Bósnia-Herzegovina \\
Allied Provider & Somália \\
Allied Harmony* & Macedônia \\
NTM-I & Iraque \\
KFOR & Kosovo \\
Active Endeavour & Mediterrâneo \\
\hline
\end{tabular}

* Estas operações persistem, ainda que as missões de paz tenham se encerrado oficialmente. A OTAN mantém quartéis-generais em Sarajevo e Skopje para dar suporte às operações da União Europeia instaladas nesses países.

Fonte: OTAN (2008a).

É interessante notar que apenas uma das operações da OTAN em andamento em 2008 envolve claramente o princípio de segurança coletiva. A primeira evocação desta cláusula na história da Aliança aconteceu em resposta aos ataques terroristas realizados no território dos 
Estados Unidos em 11 de setembro de 2001. Ainda que tenha caráter dissuasório, tal operação, iniciada com sistemas de controle aéreo enviados aos Estados Unidos, foi mantida pela Aliança na forma de controle marítimo no Mediterrâneo e integra os esforços de uma mobilização ainda maior, de sua luta antiterrorismo.

A partir de 2004, a OTAN autorizou o ingresso, em sua frota, de embarcações de nações parceiras que ofereceram apoio à operação em curso no Mediterrâneo. Em 2006, um navio russo passou a integrar a operação e, no ano seguinte, também uma fragata ucraniana. Contudo, entre os eventos destacados pela OTAN como os mais significativos desta operação, está o resgate de vítimas de acidentes na região do Mar Mediterrâneo (OTAN, 2008b).

O ativismo militar da OTAN em relação ao estabelecimento de operações militares é abordado por Martin A. Smith (2000), que concorda com a análise de Robert B. McCalla (1996) sobre a burocracia da OTAN. Esta tende a assumir a defensiva em relação a outras organizações semelhantes, para evitar perda de sua relevância: um exemplo disso é a reafirmação, por parte de altos funcionários da OTAN, de que esta deveria manter "sua liberdade de ação institucional em relação à ONU”' (SMITH, 2000, p. 172). Houve também quem defendesse a independência da Aliança para decidir sobre operações militares até mesmo em relação à OSCE.

A aliança político-militar transatlântica estaria preenchendo um declínio do ativismo humanitário da ONU? De acordo com dados oficiais, houve um aumento sem precedentes no número de missões iniciadas pela ONU a partir do final da Guerra Fria. A Figura 1 compara o número total de operações da ONU em andamento e o total de operações encerradas.

Durante a década de 1990, o Conselho de Segurança da ONU esteve particularmente ativo na resolução de conflitos, tendo lançado o maior número de novas missões em toda a sua história. Foram iniciadas 
Atuação da OTAN no Pós-Guerra Fria:

Implicações para a Segurança Internacional...

\section{Figura 1}

Gráficos Comparativos do Número de Operações de Paz da ONU

Encerradas e em Andamento
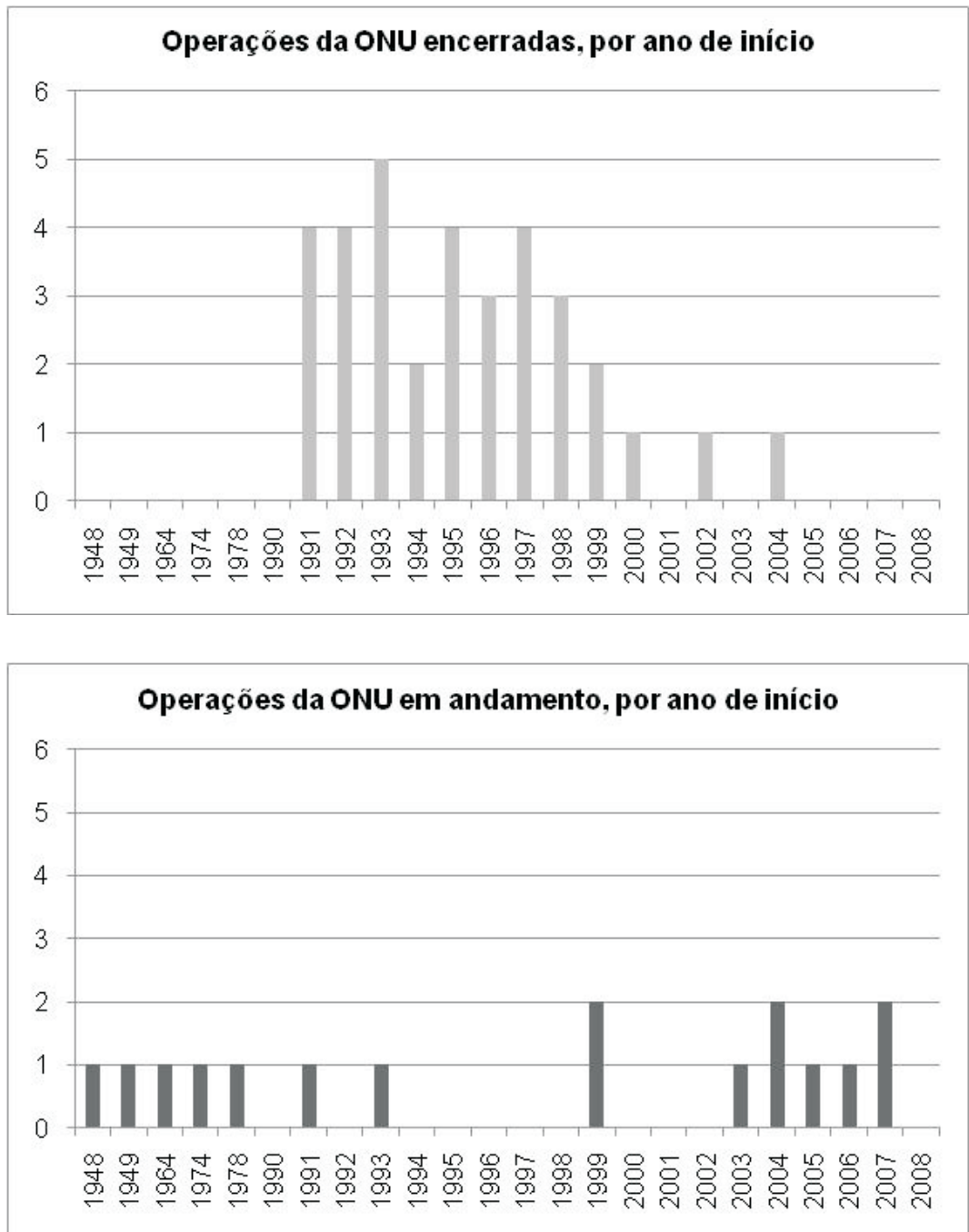

Fontes: ONU (2009) e Military Periscope (2008).

pelo menos duas novas missões a cada ano, o que corresponde ao patamar máximo dos períodos anteriores. 
A OTAN passa a se envolver em operações de paz a partir de 1992, inicialmente em complementaridade com as atividades da ONU. O número de novas missões estabelecidas pela ONU de fato apresenta um declínio no momento em que a OTAN realiza sua intervenção no Kosovo sem um mandato específico da ONU, ou até mesmo um da OSCE. A Figura 2 apresenta o número de operações da OTAN a cada ano, desde a sua primeira atuação em 1993. Os dados são apresentados de forma a permitir a comparação entre o total de operações encerradas e o total de operações em andamento em dezembro de 2008.

Se em sua primeira atuação militar a OTAN cumpriu estritamente o que foi estabelecido na Carta das Nações Unidas, servindo como capacidade aérea adicional à daquela organização, com um mandato do Conselho de Segurança para o monitoramento do embargo aéreo na Bósnia, depois disso a OTAN atuou de diversas outras formas, inclusive sem um mandato da ONU.

Um ponto particularmente interessante na análise das operações é que o recurso à OTAN, visando especialmente a utilização de suas capacidades militares de transporte aéreo, não partiu mais apenas da ONU. Em um procedimento idêntico ao observado para com o secretário-geral da ONU, pedidos de chefes de Estado, por meio de cartas ao secretário-geral da OTAN, já foram atendidos duas vezes.

A primeira delas ocorreu em resposta ao pedido do governo do $\mathrm{Pa}-$ quistão para viabilizar o envio de ajuda humanitária após um grave terremoto. A Aliança transportou as doações não só de seus membros como também as do Alto Comissariado das Nações Unidas para Refugiados (ACNUR), levando também posteriormente equipes de médicos e engenheiros para auxiliar nas tarefas de resgate e reconstrução das áreas atingidas.

A segunda ocasião também envolveu um pedido de uso de aviões, em apoio a uma missão da UA. O presidente da comissão da UA pediu 
Atuação da OTAN no Pós-Guerra Fria:

Implicações para a Segurança Internacional...

\section{Figura 2}

Gráficos Comparativos do Número de Operações de Paz da OTAN

Encerradas e em Andamento
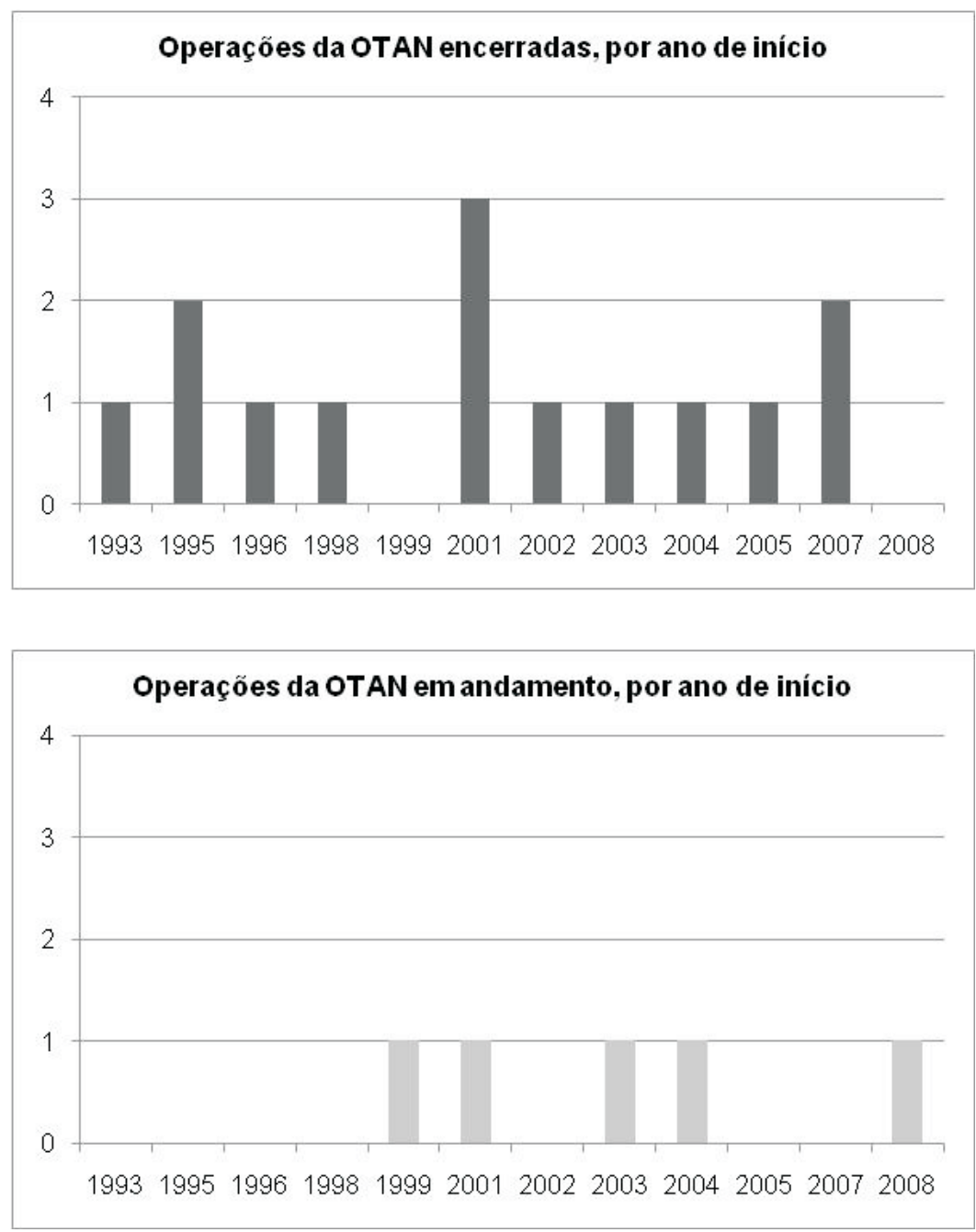

Fonte: OTAN (2008a).

apoio à OTAN para sua operação de paz em Darfur, também por meio de uma carta. A OTAN consultou a União Europeia e a ONU para de- 
terminar qual tipo de auxílio ela poderia oferecer. Depois de várias extensões de mandato, a participação da OTAN em Darfur completou dois anos, e há planos da UA para incluir a OTAN em novas missões.

A última nova missão da ONU foi lançada em setembro de 2007 e, desde então, a OTAN continua lançando novas operações. Com mandato da ONU, por exemplo, a OTAN passou a integrar em dezembro de 2008 os esforços de vários países contra a pirataria na costa da Somália e já lançou uma nova operação de apoio para esta missão.

Portanto, a hipótese de que a OTAN estaria suprindo um espaço aberto pela omissão da ONU não se confirma, pois, embora a OTAN registre um total de operações ligeiramente maior que o da ONU na primeira década do século XXI, esta não é menos ativa para o departamento de operações de paz da ONU do que as várias décadas da Guerra Fria. Ainda que em menor número em relação à década de 1990, a partir de 2002 foi mantida a frequência de estabelecimento de novas operações da ONU a cada ano, com exceção apenas de 2008 até o momento.

Em função da forma como a OTAN se insere no campo da segurança global, contudo, é necessário examinar questões ligadas à legitimidade de sua atuação militar.

\section{A Questão da Legitimidade}

A participação da OTAN em operações militares fora do território dos Estados-membros e além da cláusula de defesa coletiva contra um agressor por si só já coloca uma série de questões controversas para o cenário da segurança internacional. Uma complicação adicional surge quando esta Aliança deixa de se submeter à autorização do Conselho para iniciar operações, ainda que de alegado caráter humanitário. Quando chefes de Estado passam a solicitar intervenções di- 
Atuação da OTAN no Pós-Guerra Fria: Implicações para a Segurança Internacional...

retamente à OTAN, cria-se um precedente no relacionamento internacional que questiona o critério regional ou subsidiário reservado às organizações regionais de segurança no ordenamento internacional. Este novo padrão de comportamento da OTAN, por exemplo, já foi assumido pela União Europeia.

Conforme o estudo realizado por Albane Geslin (2005), este problema de legitimidade tem como causa tanto a atitude das organizações internacionais de segurança, quanto a do próprio Conselho de Segurança. Ao contrário do que determina a Carta das Nações Unidas, as organizações regionais de segurança não necessariamente pedem autorização prévia ao Conselho de Segurança para adotar medidas coercitivas. Por seu lado, o Conselho de Segurança evita, em suas resoluções, recorrer especificamente às organizações regionais de segurança na concessão de mandatos para ações militares.

No caso da intervenção internacional no Afeganistão, em termos legais a OTAN atua como uma coalizão multilateral com mandato da ONU. A partir de um período de comando rotativo com envolvimento individual dos Estados-membros, a OTAN só passa a assumir o controle operacional dois anos após o início da operação ISAF.

Este problema prático abre espaço tanto para ações ilegais das organizações quanto para a perda de autoridade do Conselho de Segurança. Para tentar legitimar suas ações, as organizações recorrem a "habilitações implícitas", em geral referentes aos membros da ONU e que são estendidas às organizações em decorrência de suas próprias interpretações do texto de resoluções adotadas pelo Conselho de Segurança.

Para a intervenção da OTAN em Kosovo, por exemplo, este tipo de tentativa de legitimação falhou, já que na Resolução em questão não há a autorização para o recurso à força (GESLIN, 2005, p. 35-36). ${ }^{8}$ Já para uma ação derivada da solicitação direta de um chefe de Estado para que a OTAN realizasse uma operação militar, como aconteceu 
no caso do Paquistão, por exemplo, a legitimidade poderia advir simplesmente do consentimento. Tal consentimento pode, contudo, ser questionado, já que é difícil determinar a existência de constrangimentos anteriores ou até posteriores à delegação de poder em favor de um interventor.

Outras organizações regionais, tais como a União Africana, possuem maior coordenação com a ONU, o que ficou evidenciado até mesmo em ocasiões nas quais a UA solicitou o apoio da OTAN para a AMIS, sua operação de paz na Somália (AFRICAN UNION, 2004). Esse é apenas um exemplo da atividade consistente com os princípios da Carta, que reforça a afirmação de Geslin (2005, p. 37): "somente a habilitação [dada pelo Conselho de Segurança] pode conferir à intervenção coercitiva de uma organização regional um fundamento jurídico".

\section{Algumas Conclusões}

Após o fim da Guerra Fria, a OTAN, considerada ao mesmo tempo uma aliança militar e uma agência de segurança regional, começa a participar de operações militares fora dos territórios de seus membros e em missões não motivadas pela segurança coletiva destes. $\mathrm{Na}$ tentativa de explicar a permanência da OTAN no pós-Guerra Fria e sua transformação, este artigo ressaltou o seu caráter dual, de aliança militar e organização de segurança, e analisou os dados sobre sua participação em operações militares.

As teorias sobre as alianças analisam arranjos localizados e ad hoc. Sua preocupação central é explicar a formação e a coesão, mas não a possível persistência das alianças na forma de instituições. A teoria realista, que domina a produção acadêmica sobre as alianças, tende a basear suas explicações sobre a manutenção prolongada destas de forma simples: em função da persistência de uma ameaça comum 
Atuação da OTAN no Pós-Guerra Fria: Implicações para a Segurança Internacional...

que inicialmente motivou a coalizão, ou da forte possibilidade de emergência de uma nova ameaça comum.

As teorias institucional e organizacional, aplicadas ao fenômeno da persistência da OTAN, envolvem os seguintes elementos: sua estrutura organizacional robusta, sua capacidade de se adaptar à mudança de cenários e de buscar novas tarefas que possa realizar quando seus objetivos iniciais estão cumpridos ou perdem a relevância.

Contendo três dos cinco membros permanentes do Conselho de Segurança da ONU, a OTAN consegue construir um consenso na área militar com certa frequência. Ainda assim, as intervenções da OTAN não são sempre identificadas como legítimas pela ONU. Até mesmo o rótulo de intervenção humanitária não está livre de questionamentos no campo da política internacional.

Os dados apresentados neste trabalho mostram que houve certo declínio no número de novas missões autorizadas pelo Conselho de Segurança da ONU na primeira década do século XIX quando comparada à década anterior. A frequência de lançamento das missões, contudo, difere de toda a história anterior, e mantém paridade com os anos 1990. No mesmo período, o número de novas operações da OTAN também cresceu, e entre os anos 2000 e 2008 atingiu um total ligeiramente maior que o registrado para a ONU no mesmo período. Mais do que isso, a atuação independente por parte da OTAN em escala global e o recurso direto à OTAN por parte de membros da ONU representam precedentes importantes.

Contudo, a questão da legitimidade de operações militares por parte de outras organizações deve ser discutida tendo como parâmetro as disposições da Carta das Nações Unidas. Representando um grupo de Estados mais restrito do que a Assembleia Geral, mas bem mais amplo do que os membros permanentes do Conselho de Segurança da ONU, a OTAN tem uma capacidade instalada e mobilizada relevante em um cenário internacional bastante conflituoso. 
O problema da legitimidade ocorre quando se verifica que esta capacidade não está à disposição apenas da ONU, nem restrita ao espaço regional, mas tem alcance global para atender unilateralmente aos interesses dos membros e eventualmente de terceiros, de forma bilateral. Tendo em vista a atuação recente da OTAN no cenário de segurança internacional, é possível, então, afirmar que uma reforma do Conselho de Segurança, e até mesmo da própria ONU, não poderá prescindir de instrumentos que mantenham a sua responsabilidade primordial sobre a paz internacional.

\section{Notas}

1. Outro forte motivo para a criação da OTAN foi, sem dúvida, a garantia da resolução pacífica das controvérsias entre os aliados na Europa, um continente marcado por grandes guerras.

2. Existe uma diferença importante entre uma estratégia de dissuasão e uma estratégia defensiva: nesta, um ator é capaz de desencorajar o ataque de um agressor porque ameaça oferecer uma forte resistência em sua própria defesa. $\mathrm{Na}$ estratégia de dissuasão, um ator desencoraja um ataque porque seu poder parece insuperável aos olhos do inimigo.

3. A literatura em inglês traz os termos free-riding e band-wagoning para descrever esse tipo de comportamento.

4. O TIAR foi largamente ignorado quando da Guerra das Malvinas/Falklands em 1982 e recebeu fraca atenção dos Estados Unidos na ocasião dos atentados de 11 de setembro de 2001, quando evocado pelo Brasil.

5. A renacionalização da defesa refere-se também à emergência de uma política europeia comum de segurança e defesa. Tal política é uma tentativa de redução da diferença de capacidades entre o pilar europeu e o norte-americano, e ao mesmo tempo uma expressão da vontade política de líderes europeus de assumir compromissos na área de segurança regional. Como exemplo desta intenção, temos as operações de paz da OTAN na Europa, que ou já passaram ao comando da União Europeia ou estão em fase de transferência de comando. 
Atuação da OTAN no Pós-Guerra Fria: Implicações para a Segurança Internacional...

6. A OTAN atendeu a um pedido do Paquistão para apoio em uma emergência humanitária. Este país havia sofrido em 2005 um forte terremoto, e a OTAN autorizou o uso de suas capacidades militares aéreas para o transporte de ajuda humanitária e, em seguida, enviou um time de engenheiros militares para ajudar o Paquistão em seus esforços de reconstrução.

7. A ONU mantém quinze operações de paz no mundo todo, das quais seis estão na África, que tem o maior número. As operações restantes estão assim divididas: uma nas Américas, duas na Ásia (exceto o Oriente Médio, região que tem outras três operações em atividade) e três na Europa.

8. A resolução 1199 de 23 de setembro de 1998, enquanto enfatiza a necessidade de evitar uma catástrofe humanitária em Kosovo e a necessidade de garantir o respeito aos direitos humanos dos kosovares, também reafirma que tais objetivos devem ser atingidos por meios pacíficos e que as atividades de estrangeiros no país se limitam a operações de monitoramento dos acordos estabelecidos. Ao fim, o documento menciona que, "em caso de descumprimento das medidas exigidas nesta resolução e na resolução 1160 (1998), o Conselho de Segurança decide considerar ação futura e medidas posteriores para manter ou restabelecer a paz e estabilidade na região" (ONU, 1998, p. 5).

\section{Referências Bibliográficas}

AFRICAN UNION. Report of the Chairperson of the Comission on the situation in Darfur, Sudan. Addis Ababa: African Union Documentation Center, 2004.

ARON, Raymond. Paz e guerra entre as nações. 2. ed. Brasília: Editora da UnB, 1986.

BULL, Hedley. The anarchical society: a study of order in world politics. New York: Columbia University Press, 1977.

CORNISH, Paul. NATO: the practice and politics of transformation. International Affairs, v. 80, n. 1, p. 63-74, 2004. 
DUFFIELD, John S. International regimes and alliance behavior: explaining NATO conventional force levels. International Organization, v. 46, n. 4, p. 819-855, 1992.

NATO's functions after the Cold War. Political Science Quarterly, v. 109, n. 5, p. 763-789, 1994.

GESLIN, Albane. Le pouvoir d'habilitation du Conseil de Sécurité: la délégation des pouvoirs du Conseil aux organizations internacionales. Arès, v. XXI, fascicule 3, p. 31-41, 2005.

GOLDSTEIN, Avery. Discounting the free ride: alliances and security in the post War World. International Organization, v. 49, n. 1, p. 39-71, 1995.

MCCALLA, Robert B. NATO's persistence after the Cold War. International Organization, v. 50, n. 3, p. 445-475, 1996.

MILITARY PERISCOPE. Peacekeeping. Military Periscope, 2008. Disponível em: <http://apps.militaryperiscope.com.ezproxy6.ndu.edu/Peacekeeping/ GroupMenu.aspx>. Acesso em: 2 mai. 2008.

MORGENTHAU, Hans J. Politics among nations: the struggle for power and peace. New York: McGraw-Hill, 1993.

OLSON, Mancur; ZECKHAUSER, Richard. An economic theory of alliances. Review of Economics and Statistics, v. 48, p. 266-279, 1966.

ONU. Charter of the United Nations. 1949. Disponível em: <http://www.un. org/aboutun/charter/index.html>. Acesso em: 30 mar. 2008.

Resolution 1199, adopted by the Security Council at its 3930th meeting, on 23 September 1998. In: Security Council Resolutions. New York: United Nations, 1998.

United Nations Peacekeeping. 2009. Disponível em: <http://www.un. org/Depts/dpko/dpko/>. Acesso em: 10 out. 2008.

OTAN. The North Atlantic Treaty. 1949. Disponível em: <http://www.nato.int/ docu/basictxt/treaty.htm>. Acesso em: 29 ago. 2006.

. New strategic concept. 1991. Disponível em: <http://www.nato.int/docu/ basictxt/b911108a.htm>. Acesso em: 21 jan. 2008. 
Atuação da OTAN no Pós-Guerra Fria: Implicações para a Segurança Internacional...

Istanbul summit reader's guide. Brussels: NATO Public Diplomacy Division, 2004.

. North Atlantic Treaty Organization - official homepage. 2008a. Disponível em: <http://www.nato.int>. Acesso em: 21 set. 2009.

Operation Active Endeavour. 2008b. Disponível em: <http://www.jfcnaples.nato.int/JFCN_operations/ActiveEndeavour/Endeavour.htm $>$. Acesso em: 5 out. 2008.

SIMON, J. NATO enlargement and Central Europe: a study in civil-military relations. Washington: NDU Press, 1996.

SMITH, M. A. NATO in the first decade after the Cold War. London: Kluwer Academic Publishers, 2000.

SMITH, Roland. A changing NATO. Nato Review Web Edition, v. 45, n. 3, p. 8-11, 1997.

WALLANDER, Celeste. Institutional assets and adaptability: NATO after the Cold War. International Organization, v. 54 , n. 4, p. 705-735, 2000.

WALT, Stephen M. Testing theories of alliance formation: the case of southwest Asia. International Organization, v. 42, n. 2, p. 275-316, 1988.

YOST, David S. NATO transformed: the alliance's new roles in international security. Washington: United States Institute of Peace, 1998.

\section{Resumo}

\section{Atuação da OTAN no Pós-Guerra Fria: Implicações para a Segurança Internacional e para a ONU}

Após a Guerra Fria, a Organização do Tratado do Atlântico Norte (OTAN) utilizou seus recursos militares pela primeira vez em um conflito. Desde então, ela vem atuando com regularidade, sob mandato da ONU ou não. Este trabalho apresenta a discussão teórica em torno da permanência da OTAN após o fim da Guerra Fria, e analisa sua transformação e seu novo papel em um contexto mundial distinto. As teorias das alianças não explicam a per- 
sistência de tal tipo de arranjo. As teorias dos regimes, por sua vez, vislumbram a permanência da OTAN em um contexto diverso, desde que ela consiga se transformar para se adaptar às novas condições. O levantamento de dados realizado sobre a atividade da ONU procura testar a hipótese de que existe um declínio do seu ativismo humanitário no período recente, abrindo espaço para que novos atores atuem no campo da segurança global. A conclusão é de que há um declínio, o qual não é, todavia, significativo em relação ao período da Guerra Fria. Portanto, mais do que uma possível omissão da ONU, a necessidade de justificar a permanência da aliança transatlântica no novo cenário estratégico surge como fator fundamental para que a OTAN assuma este caráter intervencionista e expedicionário, alheio aos seus fundamentos. A questão da legitimidade da OTAN para este tipo de missão é também discutida. São destacados, finalmente, os problemas de ordem legal da atuação da OTAN vis-à-vis a ONU na manutenção da segurança internacional, os quais estão contidos em uma questão maior: a necessidade de revisão dos arranjos globais de segurança coletiva e do Conselho de Segurança, em particular.

Palavras-chave: OTAN - Segurança Internacional - Intervenção Internacional - Conselho de Segurança da ONU

\section{Abstract}

\section{NATO's Action in the Post-Cold War Era: Implications for International Security and for the United Nations}

After the end of the Cold War, the North Atlantic Treaty Organization (NATO) used its military capabilities for the first time in actual conflict. Since then, it has been acting regularly, either under a United Nations' mandate or not. This work presents the debate in the literature on the permanence of NATO after the end of the Cold War and analyzes its transformation and new role in a distinct world context. Alliance theory does not explain the persistence of such an arrangement. Regime theory, on the other hand, allows for NATO persistence in a changed context, provided that it is able to transform itself and adapt to new conditions. The data obtained are used to test the hypothesis that there is a recent decline in UN humanitarian activism, which would make room for new actors to work on the field of global security. The conclusion is that although there is a decrease in UN activity, it is not significant compared to the Cold War 
Atuação da OTAN no Pós-Guerra Fria:

Implicações para a Segurança Internacional...

period. Thus, instead of a possible omission on the part of the UN, it is the need to justify the permanence of the transatlantic link in a new strategic scenario that rises as a key factor in explaining why NATO takes on this interventionist and expeditionary character, quite distinct from its original one. The legitimacy NATO could have or lack for this type of missions is also part of the discussion. Finally, it is stressed here that legal problems of NATO action vis-à-vis the UN are included in an overarching question: the need for review of global collective security arrangements and of the Security Council, particularly.

Keywords: NATO - International Security - International Intervention UN Security Council 